\title{
Assessment of the kinesiotherapy's efficacy in male athletes with calcaneal apophysitis
}

\author{
Ersin Kuyucu', Barış Gülenç ${ }^{1 *}$, Hüseyin Biçer ${ }^{2}$ and Mehmet Erdil ${ }^{1}$
}

\begin{abstract}
Background: The aim of the present study was to assess the efficacy of kinesiotherapy used for treating various disorders in athletes on pain and pedal functions in patients with calcaneal apophysitis.

Methods: This prospective randomized controlled study included 22 patients with calcaneal apophysitis aged 8 to 16 years presenting with heel pain among junior athletes of a professional football club. The patients were randomly grouped into two groups, with one group receiving sham tape only and the other kinesio tape. American Orthopedic Foot \& Ankle Society (AOFAS) and visual analog scale (VAS) scores were recorded before and after the treatment.

Results: The preoperative VAS score of the kinesio tape was 7, and AOFAS score was 62.4; the corresponding figures of the sham group were 6.81 and 70.5, respectively. The kinesio-tape group had a better AOFAS scores at 1st and 3rd month $(p<0.05)$. Posttreatment AOFAS score was $99.7 \pm 0.9$ for the kinesio-tape group and $97.4 \pm 3.9$ for the sham-tape group. Posttreatment VAS score was $0.1 \pm 0.3$ for the kinesio-tape group and $0.4 \pm 0.5$ for the sham-tape group $(p>0.05)$.

Discussion: Conservative treatment modalities are preferentially used for its treatment. Kinesiotherapy is one of the treatment methods for the apophysitis. In the literature, our study is the first prospective randomized trial on the efficacy of kinesio taping in calcaneal apophysitis.

Conclusions: Although kinesio taping can be effectively used for the restoration of ankle functions of athletes with calcaneal apophysitis, its role in pain is limited. Since it lacks serious side effects, it can be used in combination with or as an alternative to pharmacological treatment in this patient group.
\end{abstract}

\section{Background}

In adolescent athletes, heel pain is a common condition that affects work force [1]. In children belonging to this age group, calcaneal apophysitis is a major cause of heel pain. Calcaneal apophysitis is a self-limiting condition and affects persons of 8-15 years of age who are overweight and physically active. It is rare after the age of $13-15$ years when the calcaneal apophysis is ossified [2, 3].

Kinesiotherapy was first invented and developed by Kenzo Kase. Its principle mechanism of action is to regulate regional blood flow and thus eliminating inflammatory cytokines in the region and allowing reparative cells to arrive the region, thereby providing a relief and reducing symptoms. We aimed to study athletes with calcaneal apophysitis to assess the efficacy of kinesiotherapy, which

\footnotetext{
* Correspondence: barisgulenc@yahoo.com

${ }^{1}$ Orthopaedics and Traumatology Department, Medipol University, Tem

Avrupa Göztepe çıkışı/Bağcılar, Istanbul, Turkey

Full list of author information is available at the end of the article
}

we considered to be a potential alternative to the previously described arch taping approach [4].

\section{Methods}

This prospective study included 22 junior football players who were diagnosed with calcaneal apophysitis with clinical examination and radiography between 2016 and 2017, and all were actively engaged in football playing. Radiologically lateral calcaneal X-rays showed increased sclerosis and fragmentation of calcaneal apophysis. Those with radiologically closed calcaneal apophysis, a body mass index (BMI) greater than 25, comorbidities in addition to apophysitis, and a history of heel trauma or conservative treatment were excluded from the study.

All athletes provided informed consent before study entry. All participants were fully randomized, with one group undergoing kinesio taping and the other form of taping that mimicked kinesio taping but devoid of kinesio taping properties (sham). Both groups were applied stretching exercises, topical analgesic treatment, and 
massage therapy aimed at heel and plantar fascia. Ages, weight, and height of all patients were recorded.

Pretreatment and posttreatment 1st week and 1st, 3rd, and 6th month visual analog scale (VAS) scores as well as pretreatment, posttreatment 1st, 3rd, and, finally, 6th month American Orthopedic Foot-Ankle Society (AOFAS) scores were recorded in all patients. We used the AOFAS for the ankle and hindfoot. All patients were monitored for recurrences from the onset of treatment to the end of the 6th month. X-rays evaluation was done before taping.

\section{Tape application}

Kinesio taping was applied using the mechanical correction method recommended by Kenzo Kase for calcaneal apophysitis; as such, a 4-6-in. tape portion was cut and pulled from both ends to apply moderate to severe tension $(50-75 \%)$ in a way to intersect the insertion point of the Achilles tendon to the calcaneus perpendicularly. The knee was placed in extension and the ankle in maximum dorsiflexion during the application (Fig. 1) [4].

In contrast, sham taping was applied to the same region in a similar manner using Hypafix (BSN Medical Guilllaime Kroll, Luxembourg) hypoallergenic tape, without applying tension, and with the knee and ankle in extension and dorsiflexion positions as in the kinesio taping (Fig. 2).

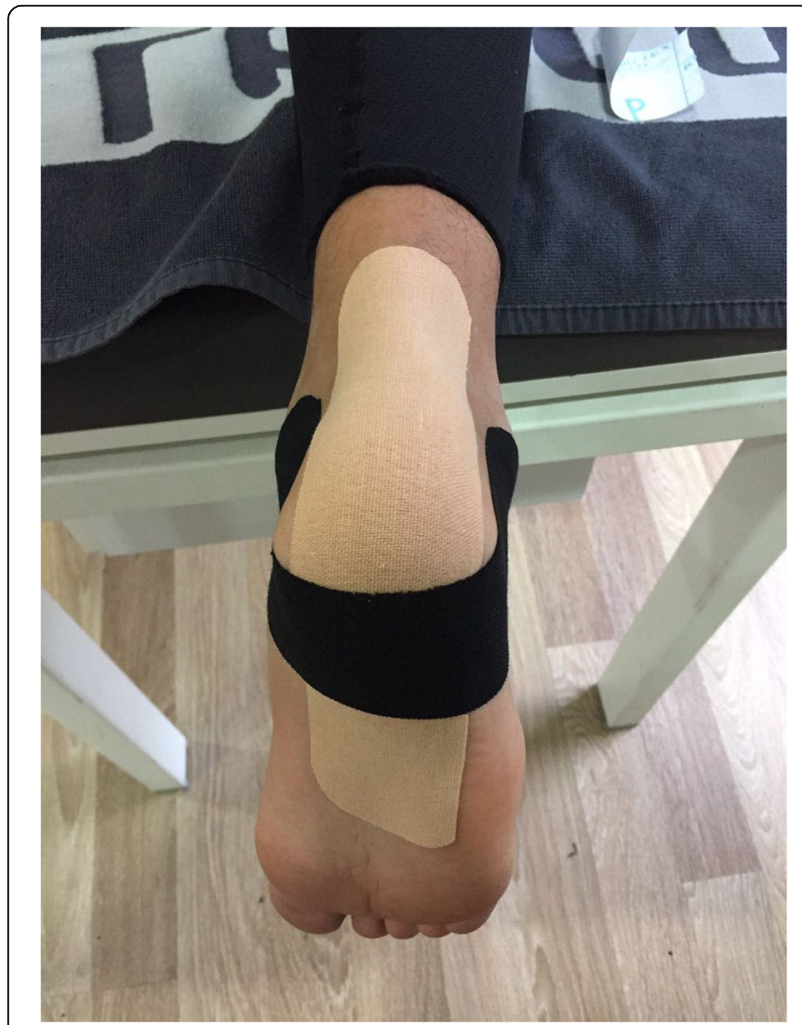

Fig. 1 Kinesio taping treatment applied to the Achilles tendon and heel region

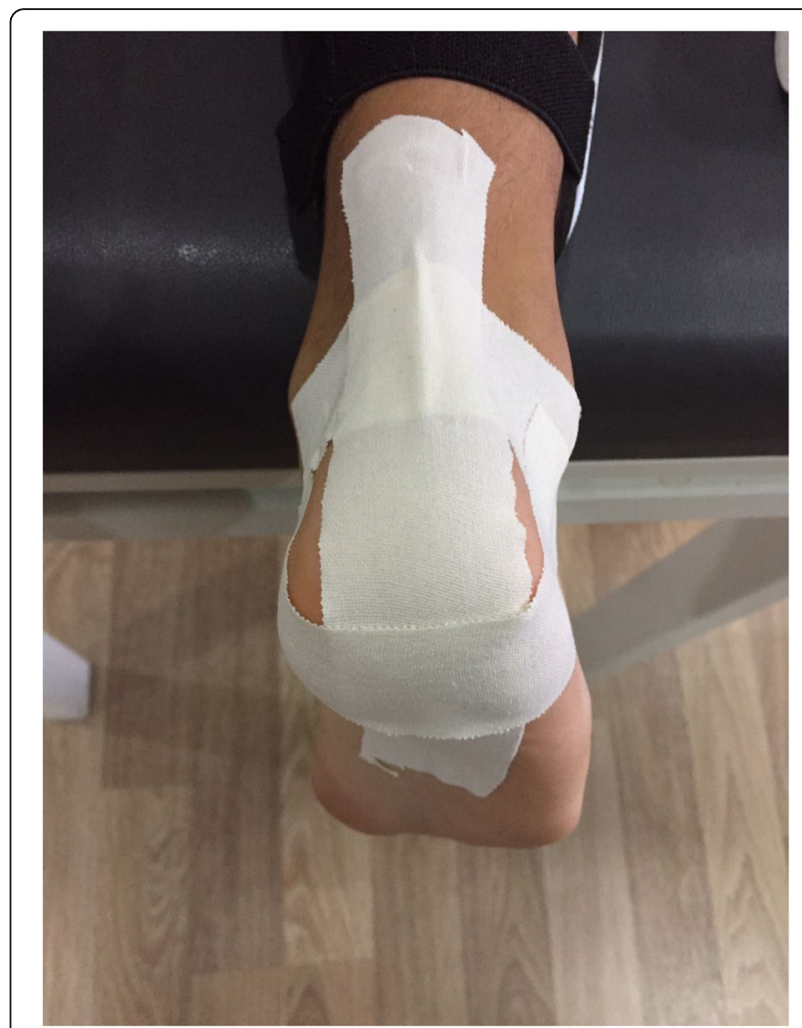

Fig. 2 Sham taping applied to the same region

Taping was repeated by an expert physiotherapist every 3 days, with 1 day intervals between two consecutive sessions in order to rest the skin. By this way, a total of 12 kinesio taping procedures were carried out and the therapy was terminated.

\section{Statistical analysis}

The descriptive statistics included mean, standard deviation, median, minimum, maximum, frequency, and percentage. The distribution of the study variables was tested using Kolomogorov-Smirnov test. Independent quantitative variables were compared using independent samples $t$ test and Mann Whitney $U$ test. Dependent quantitative data were analyzed with Wilcoxon test. SPSS 22.0 software package was used for all statistical analyses.

\section{Results}

In this study, we included 27 patients with calcaneal apophysitis with radiologic and clinical diagnosis. Three patients whose BMI $>25$ and two patients who have trauma history were excluded. After excluding the above patients, the study was finished with $22 \mathrm{pa}-$ tients. All patients were male. The study population had an age range of 10-16 years, the mean age of the study participants was $13.18(10-16)$ years, and their mean BMI was 19.6 (17-22). 
When we compared the kinesio and sham taping groups, they did not show significant differences in terms of 1st week, 1st month, 3rd month, and 6th month VAS scores ( $p$ $>0.05$ ) (Table 1). But in itself, Kinesio group showed a significantly decreased 1st week, 1st month, 3rd month, and 6th month VAS scores compared to the pretreatment VAS score $(p<0.05)$. Likewise, in the sham group, the 1st week, 1st month, 3rd month, and 6th month VAS scores showed significant reductions compared to the pretreatment VAS score $(p<0.05)$ (Table 1$)$. Both groups were comparable with respect to the 1st week, 1st month, 3rd month, and 6th month VAS score reductions compared to the pretreatment VAS score $(p>0.05)$ (Table 2, Fig. 3).

The kinesio and sham groups did not show significant differences between pretreatment and 6th month AOFAS scores $(p>0.05)$. The Sham group showed significant increases in 1st month, 3rd month, and 6th month AOFAS scores compared to the pretreatment AOFAS score $(p$ $<0.05$ ) (Table 2). The kinesio group had significantly higher than the 1st month and 3rd month AOFAS scores compared to the sham group $(p<0.05)$ (Table 2 , Figs. 3 and 4). Posttreatment AOFAS score was $99.7 \pm 0.9$ for the kinesio-tape group and $97.4 \pm 3.9$ for the sham-tape group. Posttreatment VAS score was $0.1 \pm 0.3$ for the kinesio-tape group and $0.4 \pm 0.5$ for the sham-tape group $(p>0.05)$.

\section{Discussion}

In this prospective study, we explored no significant differences between both groups with regard to age, weight,

Table 1 VAS alteration of both groups before and during treatment

\begin{tabular}{|c|c|c|c|c|c|}
\hline & \multicolumn{2}{|l|}{ Kinesio tape } & \multicolumn{2}{|l|}{ Sham tape } & \multirow[t]{2}{*}{$p$} \\
\hline & Median \pm SD & Median & Median \pm SD & Median & \\
\hline \multicolumn{6}{|l|}{ VAS } \\
\hline Pretreatment & $7.0 \pm 0.9$ & 7.0 & $6.8 \pm 1.2$ & 7.0 & $0.783^{a}$ \\
\hline 1st week & $5.5 \pm 0.9$ & 6.0 & $5.4 \pm 2.1$ & 6.0 & $0.893^{\mathrm{a}}$ \\
\hline 1st month & $2.8 \pm 0.6$ & 3.0 & $3.3 \pm 2.0$ & 3.0 & $0.812^{\mathrm{a}}$ \\
\hline 3rd month & $0.5 \pm 0.5$ & 1.0 & $1.5 \pm 1.2$ & 1.0 & $0.069^{a}$ \\
\hline 6th month & $0.1 \pm 0.3$ & 0.0 & $0.4 \pm 0.5$ & 0.0 & $0.136^{\mathrm{a}}$ \\
\hline \multicolumn{6}{|c|}{ Change relative to pretreatment period } \\
\hline 1st week & $1.5 \pm 0.5$ & 2.0 & $1.5 \pm 1.2$ & 1.0 & $0.782^{a}$ \\
\hline Change $p$ & $0.003^{b}$ & & $0.011^{b}$ & & \\
\hline 1st month & $4.2 \pm 0.9$ & 4.0 & $3.5 \pm 1.5$ & 4.0 & $0.199^{a}$ \\
\hline Change $p$ & $0.003^{b}$ & & $0.003^{b}$ & & \\
\hline 3rd month & $6.5 \pm 1.1$ & 6.0 & $5.4 \pm 1.4$ & 5.0 & $0.057^{\mathrm{a}}$ \\
\hline Change $p$ & $0.003^{b}$ & & $0.003^{b}$ & & \\
\hline 6th month & $6.9 \pm 1.0$ & 7.0 & $6.5 \pm 1.1$ & 7.0 & $0.341^{\mathrm{a}}$ \\
\hline Change $p$ & $0.003^{b}$ & & $0.003^{b}$ & & \\
\hline
\end{tabular}

${ }^{a}$ Mann-Whitney $U$ test $/ X^{2}$

${ }^{2}$ chi square test
Table 2 AOFAS alteration of both groups before and after treatment

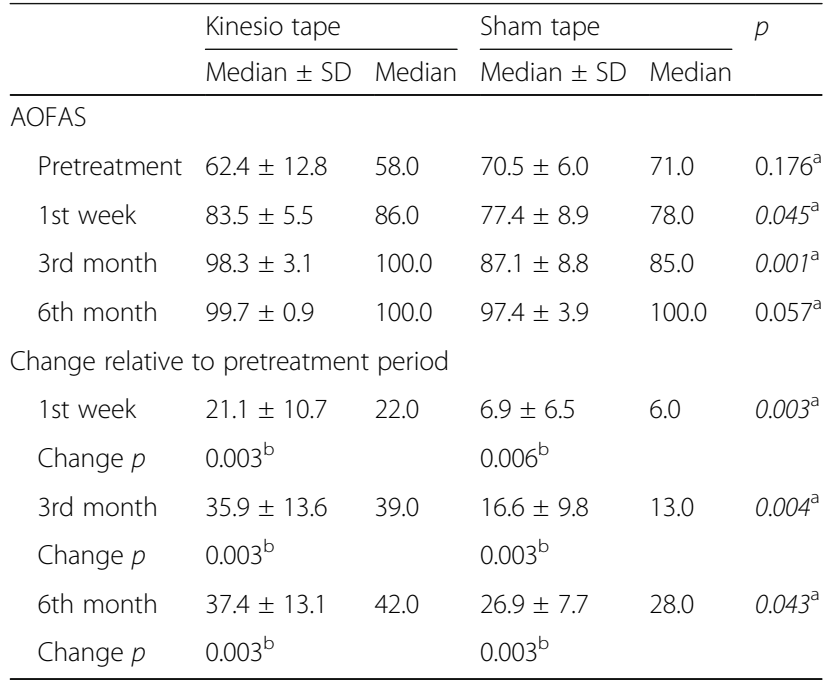

a Mann-Whitney $U$ test $/ X^{2}$

${ }^{2}$ chi square test

statistical differences of AOFAS scores of both groups (italics)

height, and body mass index (Table 3). No significant difference was found between the VAS scores of both groups. The results of the present study showed that the AOFAS score used for assessing ankle functions after kinesiotherapy was significantly increased in the kinesiotherapy group compared to the sham group. On the other hand, no significant difference was found between the two groups with respect to score increase.

Calcaneal apophysitis pathogenesis is thought to involve inflammation resulting from calcaneal apophysis being subjected to shear forces due to its constant traction by Achilles tendon and plantar fascia, as well as the excessive increase in the intensity of the traction force on apophysis as a result of the Achilles tendon being unable to keep pace with the tibial and fibular growth peak and remaining relatively "short" $[5,6]$. The disease is characterized by heel pain, antalgic gait, limited ankle dorsiflexion, and performance loss in young athletes engaged in football and is diagnosed when a patient feels pain in the compression test. Direct films may show increased sclerosis and fragmentation of calcaneal apophysis [3] (Fig. 5). Advanced imaging techniques such as CT, MRI can be used to exclude conditions such as osteomyelitis or malignancy which are included in the differential diagnosis.

Conservative treatment modalities are preferentially used for its treatment. These include non-steroidal antiinflammatory drugs, massage therapy, cold application, foot orthosis, and arch taping [7].

Direct forces acting on calcaneus apophysis are the traction forces that the plantar fascia and Achilles tendon apply in opposite directions. In normal walking cycle, 


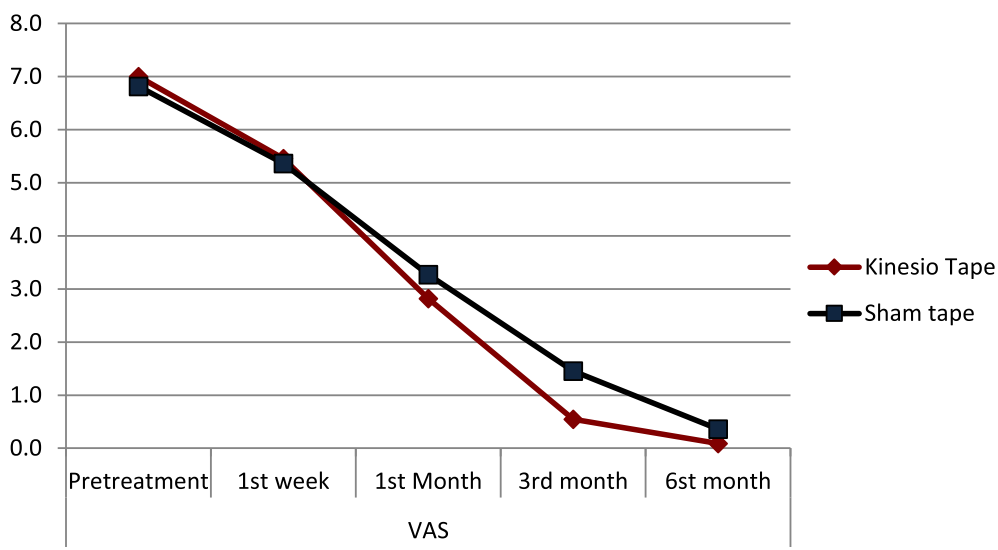

Fig. 3 Line graph of VAS alteration during treatment

in the initial contact phase, when the foot contacts the floor, the talonavicular joint displaces distally, the ankle makes internal rotation and pronation, and the plantar fascia becomes tenser. Tense plantar fascia causes a pressure increase in calcaneus apophysis [8-10].

With the continuation of the walking cycle, shortening of the Achilles tendon increases its tension, further increasing load transfer onto calcaneal apophysis [11-13]. The plantar fascia starts in the medial tubercle and attaches to the base of toes. In the late phase of the cycle, when heel elevation takes place, the plantar fascia is folded beneath the convex surface of the metatarsal heads with the dorsiflexion of the metatarsophalangeal joints (the windlass mechanism) $[8,9]$.

Again, during this phase of walking, the length of the Achilles tendon is significantly shortened and the traction forces on the calcaneus' center of growth become maximum, causing microavulsions $[14,15]$.

In our study, we also observed that the improvement of some patients' complaints occurred too late in the course. The literature data shows an average healing time of several weeks to 2 months [16]. We consider that in persons intensely performing the late swinging phase activity of walking (during shooting or sprinting), such as football players, calcaneal apophysitis is caused by microtraumas in plantar fascia due to repetitive trauma healing with fibrosis, resulting in shortening that slightly further increase the load on calcaneal apophysis. Hence, we think that patients' complaints are not fully eliminated without this shortening being corrected. What matters here is to determine in which patients fibrosis develops and to predict which athletes would return to sports and when.

Rachel et al. sought to answer the question whether all patients have to undergo radiography to make diagnosis. They reported that pathologies other than calcaneal apophysitis potentially causing severe heel pain were present in $5.1 \%$ of 96 patients and that a lateral film should be taken in every patient with heel pain and a positive compression test [17]. We also took lateral foot radiograms for every patient. No athlete was found to have any pathology other than calcaneal apophysitis causing heel pain. Some patients had fragmentation, and some others had increased sclerosis. But we did not classify the X-rays

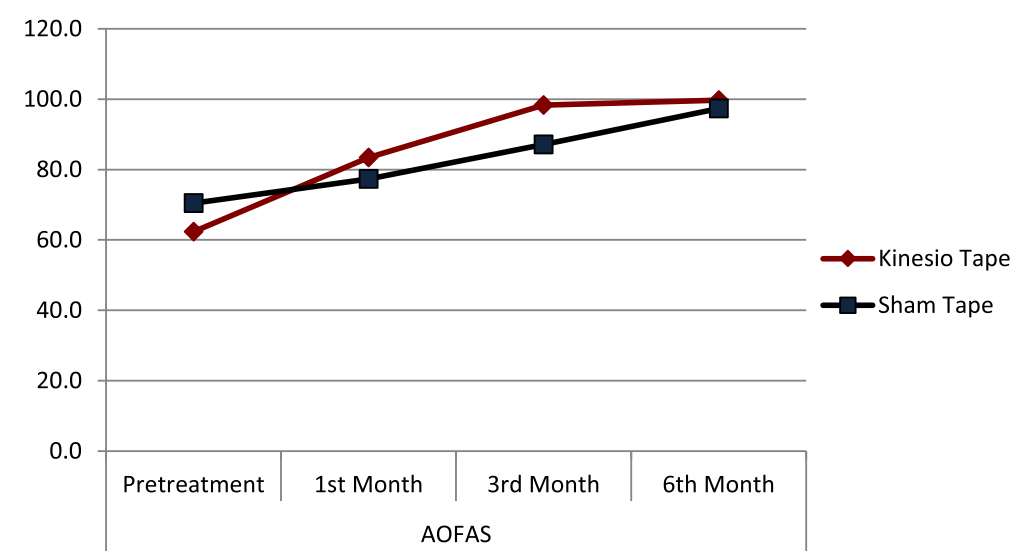

Fig. 4 Line graph of AOFAS alteration during treatment 
Table 3 Baseline characteristics of the study population with kinesio and sham taping

\begin{tabular}{|c|c|c|c|c|c|}
\hline & \multicolumn{2}{|l|}{ Kinesio tape } & \multicolumn{2}{|l|}{ Sham tape } & \multirow[t]{2}{*}{$p$} \\
\hline & Median \pm SD & Median $\pm S D$ & Median \pm SD & Median & \\
\hline Age & $13.0 \pm 2.2$ & 14.0 & $13.4 \pm 2.1$ & 13.0 & $0.699^{2}$ \\
\hline Height & $168.6 \pm 4.9$ & 168.0 & $173.7 \pm 4.3$ & 174.0 & $0.051^{b}$ \\
\hline Weight & $58.6 \pm 3.8$ & 59.0 & $59.5 \pm 3.1$ & 60.0 & $0.530^{b}$ \\
\hline BMI & $20.6 \pm 1.0$ & 20.4 & $19.8 \pm 1.5$ & 19.9 & $0.131^{b}$ \\
\hline
\end{tabular}

${ }^{a} t$ test

${ }^{\mathrm{b}}$ Mann-Whitney $U$ test $/ X^{2}$ chi square test

taken for the elimination of other pathologies to exclude or include the patients. Our hypothesis related to this finding is that fragmentation occurs as a result of an excessively increased load on heel apophysis in patients with shortened plantar fascia secondary to sclerosis.

Hundreds of studies have been conducted on the efficacy of kinesio taping since its first introduction; it has been reported to have favorable effects in a considerable portion of these studies [18-25].

We are of the opinion that one of the major reasons of the absence of any significant difference between kinesio taping and sham taping is that the former not altering plantar fascia tension. The force applied by the plantar fascia with the winding wheel mechanism is as effective as the traction force applied by the Achilles tendon on the development of apophysitis [16]. Hence, we suggest that kinesiotherapy on the Achilles tendon alone without taping the plantar fascia would not provide adequate efficacy. Although it appears technically simple to tape the plantar fascia, the efficacy of kinesiotherapy wanes when applied in constantly perspiring feet of athletes with long training hours. We did not apply arch taping or kinesio taping as described in the literature due to difficulties in application.

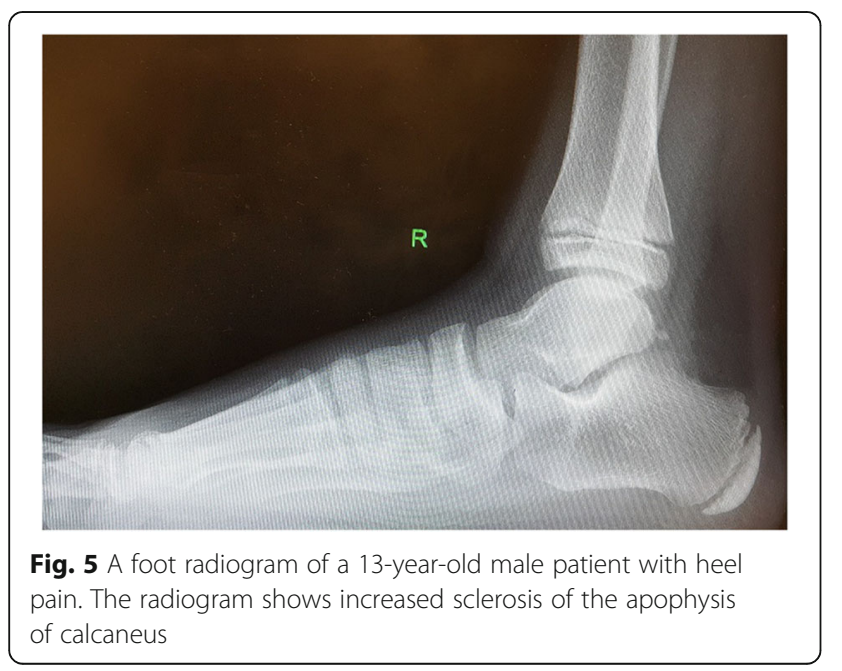

The major strength of the present study is being the first prospective randomized trial on the efficacy of kinesio taping in calcaneal apophysitis. The others include studying the procedure's efficacy on professional footballers and assessing not only pain but also providing a functional assessment.

The limitations of the study include a small sample size and the absence of an assessment of arch banding which has been performed in previous studies and has proven efficacy.

\section{Conclusions}

Kinesiotherapy was an effective treatment modality to reduce pain compared to placebo in patients with calcaneal apophysitis. Kinesio taping was significantly more effective than placebo when ankle and foot functional scores were considered.

In addition to taping, treatment modalities such as massage and manual therapy aiming at relieving plantar fascia tension can still be utilized in this age group as the most effective treatment modalities as in the past.

\section{Abbreviations}

AOFAS: American Orthopedic Foot and Ankle Society; BMI: Body mass index; $C T$ : Computed tomography; MRI: Magnetic resonance imaging; VAS: Visual analog scale

\section{Acknowledgements}

There are no funding resources or acknowledgements.

\section{Availability data and materials}

Data sharing is not applicable to this article, as no data sets were generated or analyzed during the study.

\section{Funding}

There are no funding resources for this paper.

Authors' contributions

BG and EK planned the study and writing. HB coordinated the application of physiotherapy and kinesio taping. EK and ME moderated and analyzed the study. All authors read and approved the final manuscript.

Ethics approval and consent to participate

The medical ethics committee of the Istanbul Medipol University (Istanbul, Turkey) approved this study with the decision number 10840098-604.

\section{Consent for publication}

Written informed consents were obtained from the patients for publication of these cases and accompanying images.

Competing interests

The authors declare that they have no competing interests.

\section{Publisher's Note}

Springer Nature remains neutral with regard to jurisdictional claims in published maps and institutional affiliations.

\section{Author details}

${ }^{1}$ Orthopaedics and Traumatology Department, Medipol University, Tem Avrupa Göztepe çıkışı/Bağcılar, Istanbul, Turkey. ${ }^{2}$ Physiotherapy Department, Medipol University, Tem Avrupa Göztepe çıkışı/Bağcılar, Istanbul, Turkey. 
Received: 20 June 2017 Accepted: 18 September 2017

Published online: 06 October 2017

\section{References}

1. Bailey CW, Cannon ML. Sever disease (calcaneal apophysitis). J Am Osteopath Assoc. 2014;114(5):411.

2. Wiegerinck JI, Yntema C, Brouwer HJ, Struijs PA. Incidence of calcaneal apohysitis in the general population. Eur J Pediatr. 2014;173(5):677-9.

3. Arbab D, Wingenfeld C, Rath B, Lüring C, Quack V, Tingart M Osteochondrosis of the pediatric foot. Orthopade. 2013;42(1):20-9.

4. Kenzo K, Jim W, Tsuyoshi K. Health \& Personal Care. Clinical Therapeutic Applications of the Kinesio Taping Method. 2rd Ed. 2003. p. 54-67.

5. Lewin P. Apophysitis of the os calcis. Surg Gynecol Obstet. 1926;41:578.

6. Madden CC, Mellion MB. Sever's disease and other causes of heel pain in adolescents. Am Fam Physician. 1996:54(6):1995-2000.

7. James AM, Williams CM, Haines TP. Effectiveness of interventions in reducing pain and maintaining physical activity in children and adolescents with calcaneal apophysitis. Prosthetics Orthot Int. 2013;37(6):495-8.

8. Bolgla LA, Malone TR. Plantar fasciitis and the windlass mechanism: a biomechanical link to clinical practice. J Athl Train. 2004;39(1):77-82.

9. Hicks JH. The mechanics of the foot, II: the plantar aponeurosis and the arch. J Anat. 1954:88:25-30.

10. Sarrafian SK. Functional characteristics of the foot and plantar aponeurosis under tibiotalar loading. Foot Ankle. 1987;8:4-18.

11. Donatelli RA. Abnormal biomechanics. In: Donatelli RA, editor. Biomechanics of the Foot and Ankle. 2nd ed. Philadelphia: FA Davis; 1996. p. 34-72.

12. Backstrom KM, Moore A. Plantar fasciitis. Phys Ther Case Rep. 2000;3:154-62.

13. Schwab SA. Apophyseal injuries in the growing athlete. Can Med Assoc J. 1977;117:626-30

14. Kvist MH, Heinonen OJ. Calcaneal apophysitis (Sever's disease)--a common cause of heel pain in young athletes. Scand J Med Sci Sports. 1991;1:235-8.

15. Orava S, Saarela S. Exertional injuries to young athletes. Am J Sports Med. 1978:6:68-74.

16. Micheli LJ, Ireland ML. Prevention and management of calcaneal apophysitis in children: an overuse syndrome. J Pediatr Orthop. 1987;7(1):34-8.

17. Rachel JN, Williams JB, Sawyer JR, Warner WC, Kelly DM. Is radiographic evaluation necessary in children with a clinical diagnosis of calcaneal apophysitis (sever disease)? J Pediatr Orthop. 2011;31(5):548-50.

18. Ho KY, Epstein R, Garcia R, Riley N, Lee SP. Effects of patellofemoral taping on patellofemoral joint alignment and contact area during weight bearing J Orthop Sports Phys Ther. 2017;47(2):115-23.

19. Tsai FH, Chu IH, Huang CH, Liang JM, Wu JH, Wu WL. Effects of taping on Achilles tendon protection and Kendo performance. J Sport Rehabil Mar. 2017;2:1-26

20. Huang YC, Chang KH, Liou TH, Cheng CW, Lin LF, Huang SW. Effects of Kinesio taping for stroke patients with hemiplegic shoulder pain: a double-blind, randomized, placebo-controlled study. J Rehabil Med. 2017:49(3):208-15.

21. Ortiz-Ramirez J, Perez-De la Cruz S. Efficacy of the application of kinesio tape in patients with stroke. Rev Neurol. 2017:64(4):175-79.

22. Boobphachart D, Manimmanakorn N, Manimmanakorn A, Thuwakum W, Hamlin MJ. Effects of elastic taping, non-elastic taping and static stretching on recovery after intensive eccentric exercise. Res Sports Med. 2017;25(2):1-10.

23. Keles BY, Yalcinkaya EY, Gunduz B, Bardak AN, Erhan B. Kinesio Taping in patients with lumbar disc herniation: a randomised, controlled, double-blind study. J Back Musculoskelet Rehabil. 2016;30(3):543-50.

24. Coskun Benlidayi I, Salimov F, Kurkcu M, Guzel R. Kinesio Taping for temporomandibular disorders: single-blind, randomized, controlled trial of effectiveness. J Back Musculoskelet Rehabil. 2016;29(2):373-80.

25. Balki S, Göktaş HE, Öztemur Z. Kinesio taping as a treatment method in the acute phase of $A C L$ reconstruction: a double-blind, placebo-controlled study. Acta Orthop Traumatol Turc. 2016;50(6):628-34.

\section{Submit your next manuscript to BioMed Central and we will help you at every step:}

- We accept pre-submission inquiries

- Our selector tool helps you to find the most relevant journal

- We provide round the clock customer support

- Convenient online submission

- Thorough peer review

- Inclusion in PubMed and all major indexing services

- Maximum visibility for your research

Submit your manuscript at www.biomedcentral.com/submit
) Biomed Central 